\title{
Prediction of Layer Thickness in Molten Borax Bath with Genetic Evolutionary Programming
}

\author{
Fatih Taylan \\ Department of Manufacturing Engineering, Suleyman Demirel University, Isparta 32260, Turkey \\ Reprint requests to F. T.; Tel: +90 246211 1406; Fax: +90 246237 1457; \\ E-mail: taylanf@tef.sdu.edu.tr \\ Z. Naturforsch. 66a, 193 - 198 (2011); received August 4, 2010

\begin{abstract}
In this study, the vanadium carbide coating in molten borax bath process is modeled by evolution-
\end{abstract} \\ ary genetic programming (GEP) with bath composition (borax percentage, ferro vanadium (Fe-V) \\ percentage, boric acid percentage), bath temperature, immersion time, and layer thickness data. Five \\ inputs and one output data exist in the model. The percentage of borax, Fe- $\mathrm{V}$, and boric acid, tem- \\ perature, and immersion time parameters are used as input data and the layer thickness value is \\ used as output data. For selected bath components, immersion time, and temperature variables, the \\ layer thicknesses are derived from the mathematical expression. The results of the mathematical ex- \\ pressions are compared to that of experimental data; it is determined that the derived mathematical \\ expression has an accuracy of $89 \%$.
}

Key words: VC-Coating; TD Diffusion; Borax Bath; Genetic Evolutionary Programming.

\section{Introduction}

Increasing the lifetime of the materials used in industrial applications which are reduced effects of corrosion, friction, and abrasion is possible by means of improving the surface [1]. In order to improve the surface area of the materials, ceramic coatings based on high-melting compounds such as boride, nitride, and carbide have begun to be used.

Carbides are compounds which have characteristically high hardness, electrical and thermal conductivity and stability. In addition to this, the brittleness of carbides prevented them from being used as the only material under abrasion conditions and in construction applications and resulted in the improvement of carbide coatings [2]. Carbide coating processes which are used in order to make thin hard coatings on a metal surface are carried out in main solid, liquid, and gas atmospheres.

The carburization process carried out in liquid atmosphere is simple and more cost-effective in terms of cost and mechanism compared to chemical vapour deposition (CVD) and physical vapor deposition (PVD) processes in gaseous atmosphere. When the lifetimes of the thin hard-coated and uncoated sets were compared, it was seen that the PVD coating was fragmented due to its poor adhesion strength. This is a fault stemming from the coatings which caused plastic deformation both in the process conditions and the presence of a layer on the surface [3]. The salt bath-immersion process has two advantages compared to the powder metallurgy method and CVD method seen in the coating deposition phase. If the samples are small enough to reach the bath temperature rapidly, it is easy to coat the samples in a shorter immersion time. As used in many of the studies on CVD, the shortest time in this study is also approximately 5 seconds. The other advantage is that it enables rapid cooling from the coating temperature to the quench temperature. However, if the salt adhered on the sample surface is left, this complicates the surface processes but with a well-organized cleaning process and a careful examination this situation can be avoided [4]. Chloride, floride, boraxide, and borax salt are used as the liquid bath compounds. The carburization process in the liquid atmosphere is separated into two categories as carburization in normal liquid atmosphere and carburization in molten borax bath.

Carburization in molten borax was first carried out in the 1970s at the Toyota Central Research and Development Laboratory in Japan, and it is a thermo chemical surface hardening process that occurs as a result of diffusing ferro alloys such as ferro niobium ( $\mathrm{Fe}-\mathrm{Nb}$ ), 
ferro vanadium $(\mathrm{Fe}-\mathrm{V})$, ferro chrome $(\mathrm{Fe}-\mathrm{Cr})$, which are dissolved in high-temperature borax, into the steel at $800-1200{ }^{\circ} \mathrm{C}$ for $6-8$ hours. As a result of this process, thin, hard, and well-adhered VC NbC layers which range between 2 and $15 \mu \mathrm{m}$ in thickness are obtained [5].

With the carburization process the lifetimes of the tool steels are increased between two to twentytimes [6]. The advantage of surface hardening with the carburization process in molten borax bath is that the friction coefficient is low, the surface hardness is extremely high $(\approx 2000$ Vickers $)$ and it also provides strong resistance to some solutions of acid, base, and metal and to oxidation at very high-temperature [7]. This process which is known as thermo reactive diffusion (TRD) by the scientific areas and known as Toyota diffusion process (TD) in the industry has already taken its part in various fields of automotive, chemistry, textile, and metallurgy industries in Japan.

In a study concerning the heat treatment of AISI $\mathrm{H} 13$ and D2 tool steels in the molten borax bath at $1020{ }^{\circ} \mathrm{C}$ during a four-hour process period, a bath compound which contained $\mathrm{Fe}-\mathrm{Nb}, \mathrm{Fe}-\mathrm{Ti}$, and $\mathrm{Al}$ was used. The samples were inspected with scanning electron microscopy (SEM), X-ray diffraction (XRD), energy dispersive spectroscopy (EDS), and by means of Vickers micro hardness analysis. In perfect uniformity and thickness, different layer thicknesses were obtained. The layer thickness for the AISI H13 steel was $9 \mu \mathrm{m}$ and the layer thickness for AISI D2 steel was $18 \mu \mathrm{m}$. Their micro hardness values were measured approximately as $2600 \mathrm{HV}_{0.050}$ [8]. In another study, vanadium carbide and carbo-nitride coating were coated over AISI H13 steel. It was stated that due to low carbon content of AISI H13 hot-work tool steels (approximately $0.4 \%$ ), they were not suitable for the TD process, and the coating thickness with these steels was below $10 \mu \mathrm{m}$ [9].

The thickness of the layer coating is affected by a number of parameters such as bath temperature, immersion time, carbon content in the steel, and the crucible type used in the experiment and bath compound in particular. Khoee stated that the thickness of the carbide layer changes in pure carburized steels depending on the carbon content [7]. Attempts to obtain carbide coating from armco iron which does not contain carbide were unsuccessful. In alloyed steels, the type of the alloying element affects the thickness of the carbide layer. There is a negative effect especially in the presence of carbide-forming elements in steel.
In order to obtain the intended thickness, it is necessary to carry out numerous experiments by changing these parameters. In this study a mathematical statement was derived with GEP modelling in order to reduce the number of the experiments, obtain the intended values in the shortest way, and to economize on time and cost. The experimental results for modelling are taken from the Ph.D. thesis of Khoee [7]. It will be possible to predict the layer thickness according to the bath compound chosen, the immersion time, and the bath temperature values in the molten borax bath with the derived statement in VC coated steels with carbon content of approximately $1 \%$.

\section{Genetic Evolutionary Programming (GEP)}

The evolutionary programming (EP) algorithm is composed of linear chromosomes stable in number and length which can be reproduced by the computer program. The chromosomes derived can be expressed in different shapes and dimensions in 'Explanation Trees' (ET) form using the operators of EP. EP algorithm derives target functions and values from the new chromosomes obtained randomly using one or more genetic operators such as genetic algorithm (GA) and genetic programming (GP) algorithms. The new populations obtained are the algorithms which provide the most suitable function for the target values [10].

Most of the genetic operators used in GA and GP were used in EP with slight changes.

Like GP, GEP has five main compounds: function adjustment, constants, compatibility function, control parameters, and stop condition. When solving a GEP problem these compounds are to be determined. GEP uses character rows in stable length in the solutions it offers, when their compatibilities are evolved afterwards different dimensions and shapes are expressed as the explanation tree.

In the EP algorithm, all the problems, from the simplest to the most complicated, are expressed as ETs. ETs are composed of operators, functions, constants, and variables. For example in a chromosome list EP variables such as $\{+,-, *, /$, sqrt, $1, \mathrm{a}, \mathrm{b}, \mathrm{c}, \mathrm{d}$, sin, $\cos \}$ are possible. Here, when a chromosome as sqrt.*.+.*.a.*.sqrt.a.b.c./.1.-.c.d is formed, in this chromosome full stop '? represents 'sqrt' square root operation for dividing each gene and easy reading; ' 1 ', represents a constant; ',,$+- *$ ' represent algebraical statements and ' $a, b, c, d$ ' represent the names given to the variables. 


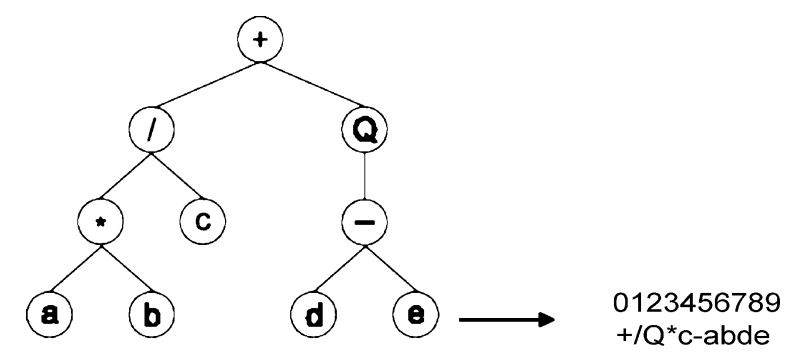

Fig. 1. Example to the mathematical explanation tree (ET).
The relationship between the variables is stated as Karva notations by Candida Ferreire who developed the EP algorithm. Karva notations are expressed with 'explanation tree' (ET). The explanation tree formed with Karva notation belonging to the evolutionary programming gene is demonstrated in Figure 1 [11].

The mathematical expression of the explanation tree in Figure 1 is:

$$
\frac{a \cdot b}{c}+\sqrt{d-e}
$$

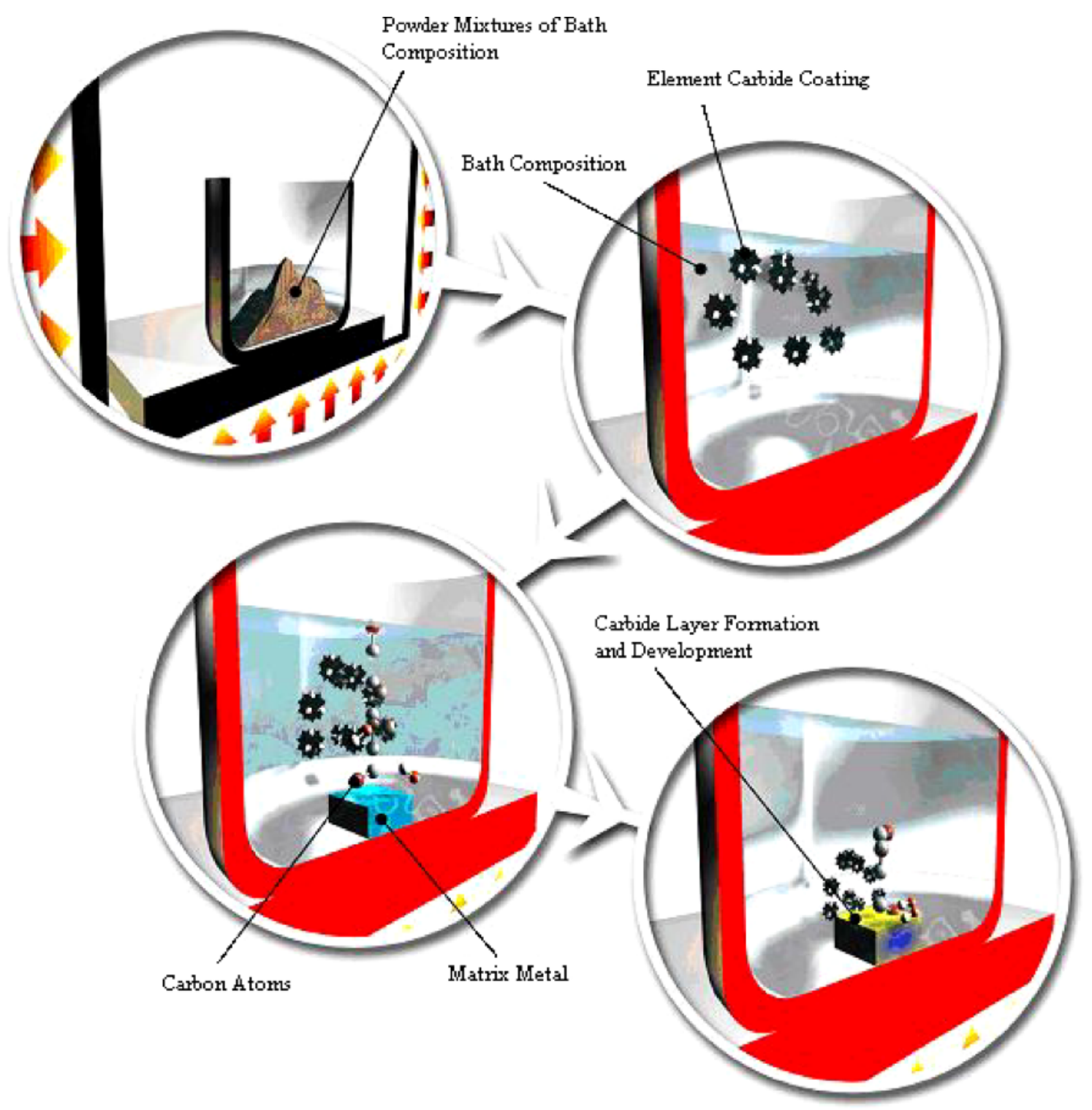

Fig. 2 (colour online). Formation of carbide layer. 
196

\section{Surface Coating and Properties}

The carbide layer is formed as a result of the reaction between its carbide-forming element atoms coming from ferro alloys dissolved in borax and the carbon atoms coming from the base metals [12].

The carbide layer on the base metal surface is formed as follows:

(i) The added carbide-forming element dissolves in the borax bath.

(ii) Carbon atoms on the base metal surface form the carbide layer as a result of the reaction with the carbide-forming element.

(iii) The carbide layer expands by means of the reaction of the carbide-forming element atoms on the surface with the carbon atoms feeding continuously from the base metal (Fig. 2).
F. Taylan · Prediction of Layer Thickness in Molten Borax Bath

Table 1. Parameters used in experimental studies [7].
Borax (\%)

$\mathrm{Fe}-\mathrm{V}(\%)$

Boric acid (\%)

Immersion time $(\mathrm{h})$

Temperature $\left({ }^{\circ} \mathrm{C}\right)$

Layer thickness $(\mu \mathrm{m})$
$95,90,89,88,87,86,85,80,75,70,65$, $60,55,50,45$

$30,25,20,15,10,9,8,7,6,5$,

$30,25,20,15,10,5,0$

$2,3,4,5,6$

$850,920,940,990,1050$

$0-27$

\section{Modelling Molten Borax Bath Compound with Genetic Evolutionary Programming}

In genetic evolutionary programming the molten borax compounds (borax \%, Fe-V \%, boric acid \%), immersion time, and bath temperature values were

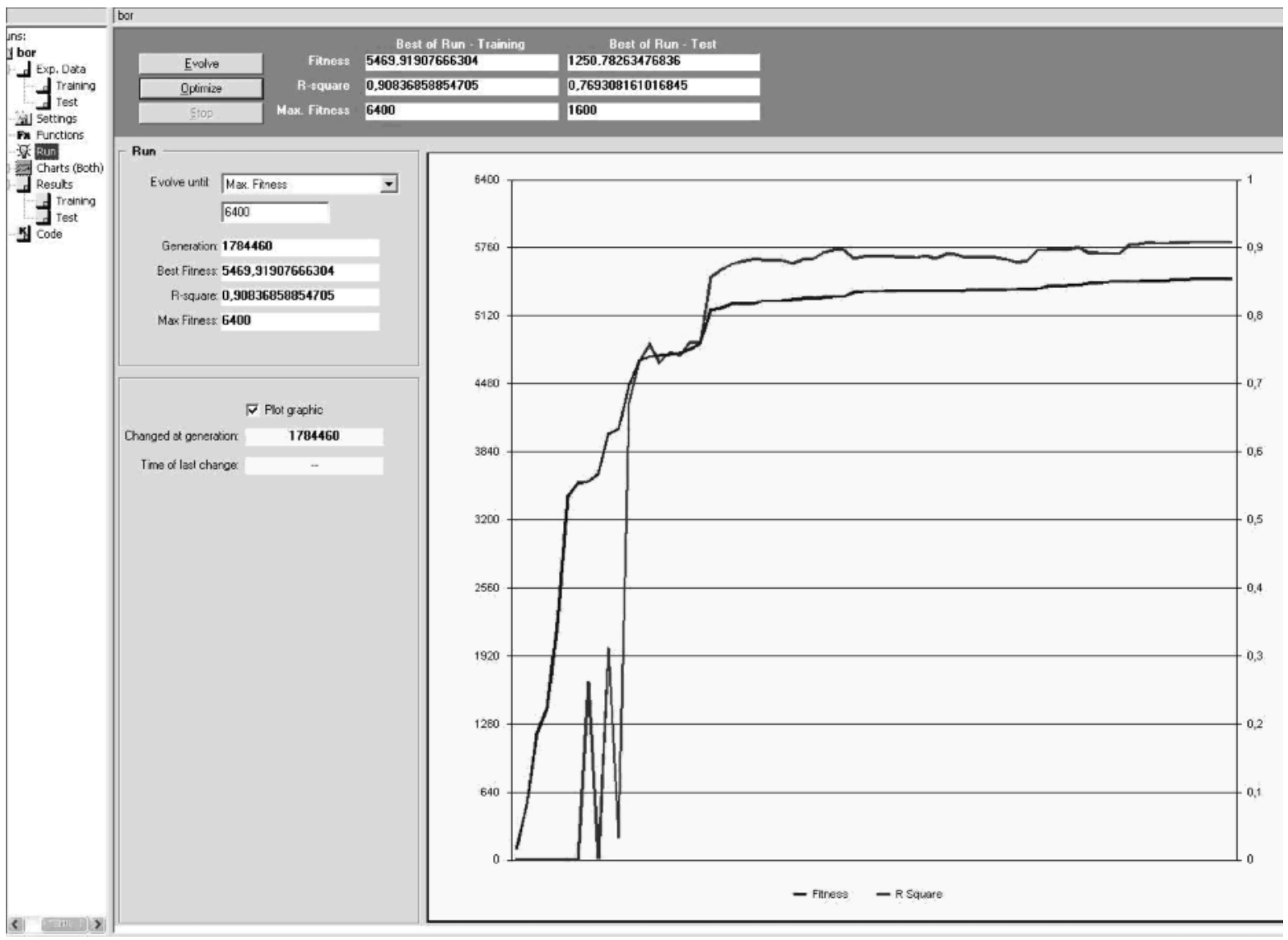

Fig. 3. Evolutionary programming model for prediction of layer thickness. 
considered as input data and the layer thickness values were considered as output data. All the genetic evolutionary data were obtained from the doctorate thesis research by Khoee [7].

In the experimental studies, Khoee carried out 80 different experiments in $115 \mathrm{CrV} 3$ work pieces by changing the bath compounds, bath temperature, and immersion time values and obtained different layer thicknesses (Tab. 1).

While modelling, 64 experimental parameters corresponding to $80 \%$ of the parameters of this experiment were used in the training part of the modelling and the 16 experiment parameters left corresponding to $20 \%$ were used in the test part of the modelling. A number of evolutionary models were built up by changing these parameters and functions in evolutionary programming in each model. The training and test data were continuously interchanged until the best possible values were obtained. As a result of the attempts, the most suitable training and test input parameters and function choice for modelling were found.

Experimental data obtained using different bath compounds were exposed to 0.044 mutation processes by being divided into 50 chromosomes and the model which made accurate predictions corresponding to 0.91 in the training data of the model and corresponding to 0.77 in the test data was formed as a result of 1784460 iterations (Fig. 3). In the created model, addition $(+)$, deduction $(-)$, multiplication $(*)$, division $(/)$, exponent $\left({ }^{\wedge}\right)$ square $\operatorname{root}(\mathrm{Q}), \ln (\mathrm{L}), 10^{\wedge} \mathrm{x}(\sim)$, sinus $(\mathrm{S})$, and tangent $(\mathrm{T})$ were used.

The $\mathrm{C}++$ code of the model by means of which $91 \%$ accuracy rate was obtained using the training data is given below:

double APSCfunction(double $\mathrm{d}[]$ )

$\{$ double dblTemp $=0$;

$$
\begin{aligned}
\text { dblTemp }+= & (\sin (\mathrm{d}[1]) *(((\mathrm{~d}[3]+\mathrm{d}[0]) \\
& *(\mathrm{~d}[0] * \mathrm{~d}[0])) * \operatorname{pow}(\mathrm{d}[4], \mathrm{d}[3]))) \\
\text { dblTemp }+= & (\operatorname{pow}(\mathrm{d}[4],(\operatorname{pow}(\mathrm{d}[1], \mathrm{d}[3]) / \\
& \operatorname{pow}(\mathrm{d}[4], \mathrm{d}[4]))) * \operatorname{sqrt}(\mathrm{d}[4])) \\
\text { dblTemp }+= & (\sin (\sin (\sin ((\operatorname{sqrt}(\mathrm{d}[1]) \\
& * \tan (\mathrm{d}[3])))))-\mathrm{d}[4])
\end{aligned}
$$

return dblTemp; $\}$.

The mathematical expression of the $\mathrm{C}++$ code is:

$$
\begin{aligned}
\mathrm{LT}= & 27 \times[(\sin ((\mathrm{d} 1-5) / 25)) \times(((\mathrm{d} 3-850) / 200) \\
& +((\mathrm{d} 0-45) / 50) \times((\mathrm{d} 0-45) / 50)^{2}
\end{aligned}
$$

$$
\begin{aligned}
& \left.\left.\times((\mathrm{d} 4-2) / 4)^{((\mathrm{d} 3-850) / 200)}\right)\right) \\
& +\left(\frac{((\mathrm{d} 4-2) / 4)^{((\mathrm{d} 1-5) / 25)^{((\mathrm{d} 3-850) / 200)}}}{((\mathrm{d} 4-2) / 4)^{((\mathrm{d} 4-2) / 4)}}\right. \\
& \cdot \sqrt{((\mathrm{d} 4-2) / 4)}) \\
& +(\sin (\sin (\sin ((\sqrt{((\mathrm{d} 1-5) / 25)} \\
& \times \tan ((\mathrm{d} 3-850) / 200)))))-((\mathrm{d} 4-2) / 4)] \text {. }
\end{aligned}
$$

In this mathematical statement, the expressions are: $\mathrm{LT}=$ layer thickness, $\mathrm{d} 0=$ borax content $(\%), \mathrm{d} 1=$ $\mathrm{Fe}-\mathrm{V}$ content $(\%), \mathrm{d} 2=$ boric acid content $(\%), \mathrm{d} 3=$ bath temperature $\left({ }^{\circ} \mathrm{C}\right), \mathrm{d} 4=$ immersion time $(\mathrm{h})$.

The layer thickness values obtained by both experimental and mathematical methods were compared (Fig. 4).

By using this mathematical model, it is possible to make an approximately $89 \%$ accurate layer thickness prediction even when the bath compounds for $115 \mathrm{CrV} 3$ steel are changed. The mathematical statement will help to make layer thickness predictions for other steels with carbon rates close to that of the steel used here (approximately 1\%).

In an experimental study carried out using 100Cr6 steel material and $85 \%$ borax and a bath compound containing $15 \% \mathrm{Fe}-\mathrm{V}$, the samples were coated with

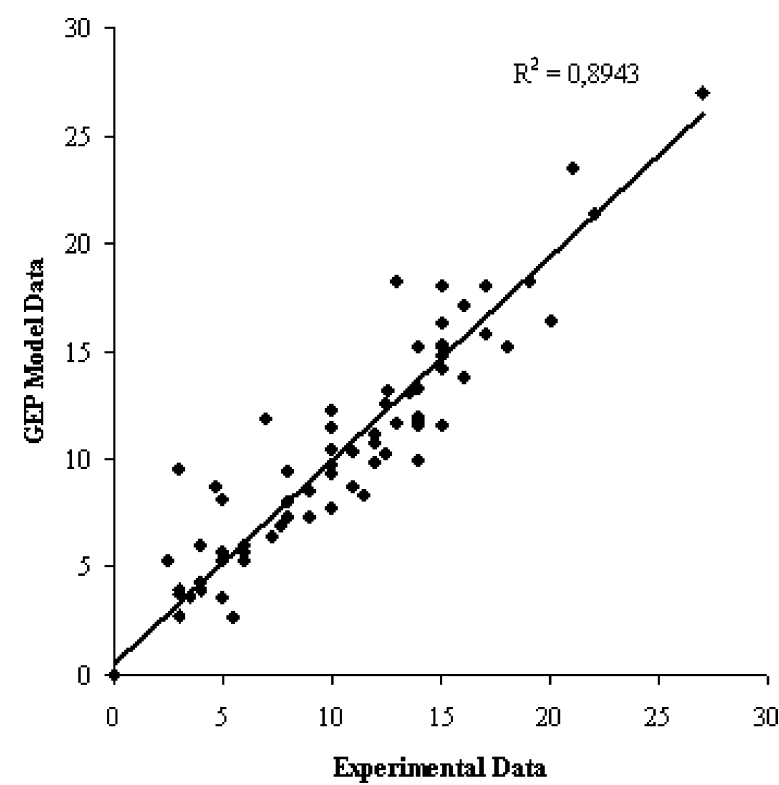

Fig. 4. Comparison of the layer thickness values obtained from the experiments and the model. 


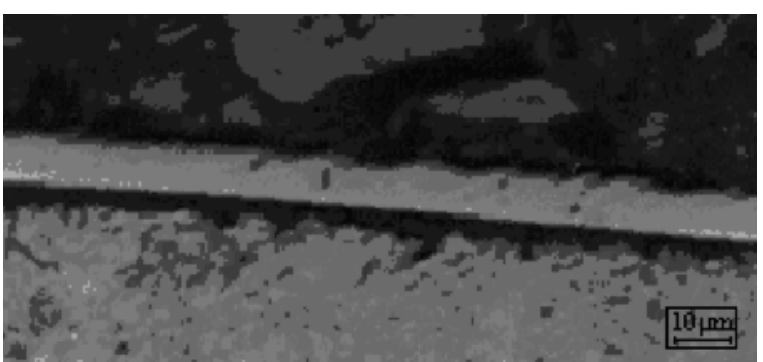

Fig. 5. Microstructure photograph of $100 \mathrm{Cr} 6$ material during the 6-hour immersion at $900{ }^{\circ} \mathrm{C}$ [1].

VC by immersion at $900^{\circ} \mathrm{C}$ for 6 hours [1]. As a result of this experiment a $9.5 \mu \mathrm{m}$-layer thickness was obtained (Fig. 5).

When the same bath compounds were replaced by the mathematical statement by means of which the temperature and immersion time values were obtained, the layer thickness was found as $11.3 \mu \mathrm{m}$. For the $100 \mathrm{Cr} 6$ steel, this mathematical statement could make an approximately $80 \%$ accurate prediction. It can be said that the mathematical statement obtained here can also be used for steels with carbon rates which are close to that of $115 \mathrm{CrV} 3$ steel.

[1] F. Taylan and A. Özsoy, Carbide Coating in Molten Borax Bath, Proceedings of the 1st International Boron Symposium, Kütahya Turkey, pp.119-123, October 3-4 2002.

[2] A. Ata, NbC Coating on Steels, İstanbul Technical University, M.Sc.Thesis, Institute of Science and Technology, 1992.

[3] T. Arai and H. M. Glaser, Substrate Selection for Tools Used with Hard Thin Film Coatings. Metal Forming Magazine (www.Metalforming.com), 1998.

[4] T. Arai and S. Moriyama, Thin Solid Films 249, 54 (1994).

[5] T. Arai, J. Heat Treating 1, 15 (1979).

[6] D. Toplu, Çeliklerde Difüzyonla Karbür Kaplama Teknolojisi. M.Sc.Thesis, Yildiz Technical University Institute of Science and Technology, 1997 (in Turkish).

\section{Results}

Although the carbide coating process in molten borax bath is a process which requires more cost-effective and simple equipments in comparison with the other carbide coatings, heat treatment time, preparation of the carbide-forming element in the intended grain size, and metallographic analysis of the samples is very time-consuming. It is necessary to carry out a number of experiments in order to obtain the intended layer thickness by considering the operating conditions. In this model which was formed using the evolutionary method, it will not be necessary to carry out a number of experiments and therefore the method will be both cost and time effective. The chosen bath compound, temperature, and immersion time are used as input data and the model gives the coating thickness values. However it should be noted here that the training and test data used for creating the model are the results of experiments carried out on $115 \mathrm{CrV} 3$ steel. The result that the model will give is only valid for this steel. Since the carbon rate in steel directly affects the layer thickness, $115 \mathrm{CrV} 3$ steel can also be used on the formed network for alloyed steels with similar carbon content.

[7] S. M. M. Khoee, Ergimiş Boraks Banyosunda Çeliklere Vanadyum Karbür Kaplama, Ph.D.Thesis, İstanbul Technical University, Institute of Science and Technology, 1992.

[8] C. K. N. Oliveira, R.M. Muñoz Riofano, and L.C. Casteletti, Mater. Lett. 59, 1719 (2005).

[9] B. Chicco, W. E. Borbidge, and E. Summerville, Mater. Sci. Eng. A266, 62 (1999).

[10] C. Ferreira, Complex Syst. 13, 87 (2001).

[11] C. Ferreira, Mutation, Transposition, and Recombination. An Analysis of the Evolutionary Dynamics, 4th International Workshop On Frontiers In Evolutionary Algorithms, pp. 614-617, Research Triangle Park, North Carolina, USA 2002.

[12] A. Ata, S. M. M. Khoee, and M. Usta, Çelikler Üzerine NbC Kaplama, 7th International Congress on Metallurgy and Materials 2 (1993) 1311-1317 (in Turkish). 